\title{
The Influence of Crystallization and Washing Medium on the Characteristics of Nanocrystalline Y-TZP
}

\author{
C. D. Sagel-Ransijn, A. J. A. Winnubst, A. J. Burggraaf \& H. Verweij \\ University of Twente, Faculty of Chemical Technology, Laboratory for Inorganic Materials Science, Enschede, \\ The Netherlands
}

(Received 30 July 1995; revised version received 26 October 1995; accepted 7 November 1995)

\begin{abstract}
A zirconia-yttria gel, made by coprecipitation, was treated in six different ways to obtain a nanocrystalline Y-TZP powder: one large gel batch was split into six parts of which one was crystallized in air and the others crystallized either in water with a high $\mathrm{pH}$ or in methanol. The batches were subjected to several post treatments. Powder properties and densification characteristics of the six powder batches obtained in this way are described. The aircalcined powder can be sintered to a relative density of about $93 \%$ at $1070^{\circ} \mathrm{C} / 10 \mathrm{~h}$, but reproducibility of the sintering characteristics is poor. Optimal hydrothermal treatment of the powder yields a reproducible sintering process, resulting in a relative density of $96 \%$ at $1070^{\circ} \mathrm{C} / 10 \mathrm{~h}$ and an average grain size between 120 and $130 \mathrm{~nm}$.
\end{abstract}

\section{Introduction}

Nanostructured materials currently receive considerable attention. The percentage of atoms present in the grain boundary region becomes significant once the grain size enters the nanometre regime (i.e. grain size less than $100 \mathrm{~nm}$ ). ${ }^{1,2}$ It is expected that the properties of these nanocrystalline ceramics will be different from those of more conventional materials with phase or grain structures on a coarser scale. ${ }^{2}$ He et $a l^{3}$ have shown that finegrained zirconia exhibits better wear resistance than the coarse-grained material. For the same material, Theunissen ${ }^{4}$ found that both bending strength and fracture toughness at high temperatures are improved with smaller grain sizes. The evaluation of mechanical properties (at low to moderate temperatures) requires the production of bodies with near-theoretical densities. However, preparing bulk materials with near-theoretical densities, while simultaneously keeping the grain size below $100 \mathrm{~nm}$, is not yet possible. The sinterability of the material should permit densification to proceed at such a low temperature that only limited grain growth occurs.

To obtain good sinterability at low temperatures, ultra-fine powders with a low degree of agglomeration are required. The compaction and sintering behaviour of such fine powders is determined, to a large extent, by the strength of their agglomerates. At a given crystallite size, the agglomerate strength can be lowered by increasing the intra-agglomerate porosity and/or decreasing the strength of the interparticle bonds. ${ }^{5}$

Fine powders of $\mathrm{ZrO}_{2}$ solid solutions can be prepared by a gel precipitation technique using metal chlorides as precursor chemicals. ${ }^{6,7}$ This so-called chloride method involves coprecipitation of metal chlorides, followed by water/ammonia and ethanol washing steps. Subjecting the gel to ethanol washing is a crucial step in lowering the strength of the agglomerates. The reduction in strength has been ascribed to the formation of ethoxide groups on the surface ${ }^{8}$ and to lower packing density within the agglomerates due to the lower surface tension of ethanol compared with water during the drying process of the powder ${ }^{9,10}$ The ethanol washing step doubles the intraagglomerate porosity after calcination (at 500$550^{\circ} \mathrm{C}$ ) compared with a gel that has been treated with water/ammonia only. ${ }^{11}$ The intra-agglomerate porosity of these alcohol-washed powders is sufficiently high to make the agglomerates collapse to a large extent under moderate pressures (50-150 $\mathrm{MPa}){ }^{7,12}$ In this way, compacts of uniform pore size distribution are obtained.

Under hydrothermal conditions, crystallization of $\mathrm{ZrO}_{2}$ solid-solution gels proceeds at temperatures well below $500^{\circ} \mathrm{C}$. For example, temperatures of $190-250^{\circ} \mathrm{C}$ have been reported for the hydrothermal 
crystallization of $\mathrm{ZrO}_{2}-\mathrm{CaO},{ }^{13} \mathrm{ZrO}_{2}-\mathrm{Y}_{2} \mathrm{O}_{3}{ }^{14-16}$ and $\mathrm{ZrO}_{2}-\mathrm{CeO}_{2} \cdot{ }^{17}$ Several investigations suggest that the formation of strong interparticle bonds under hydrothermal conditions is greatly diminished or even avoided. ${ }^{13}$ Crystallization in organic solvents might be a way to reduce the agglomerate strength even further. Sato et al. ${ }^{17}$ conclude that crystallization in organic solvents gives better results than hydrothermal crystallization to improve the sinterability, indicating the formation of softer agglomerates in organic solvents. Supercritical drying, which can be performed at a reasonable temperature and pressure for organic solvents, eliminates the effects of capillary forces and might result in even softer agglomerates.

Limited work has been done to address the differences in sinterability of $\mathrm{ZrO}_{2}$ solid solutions prepared via crystallization in air, hydrothermal crystallization and crystallization in methanol. In the case of $\mathrm{ZrO}_{2}-\mathrm{CaO},{ }^{13} \mathrm{ZrO}_{2}-\mathrm{CeO}_{2}{ }^{17}$ and $\mathrm{ZrO}_{2}$ $\mathrm{Y}_{2} \mathrm{O}_{3},{ }^{15,16}$ it has been observed that the sinterability is strongly improved by the hydrothermal treatment. None of these investigations focused on the effect of the washing medium after hydrothermal crystallization. It is expected that this step is important because it affects the surface condition and impurity level of the particles forming the agglomerates.

In this paper, Y-TZP (yttria-stabilized tetragonal zirconia polycrystals) powders are prepared from a dried ethanol-washed gel obtained by coprecipitation and crystallization in air, crystallization under hydrothermal conditions or methanol crystallization. After hydrothermal crystallization, a part of the powder is washed with ethanol. The influence of crystallization medium and post-hydrothermal crystallization treatments on powder properties, green compact structure and sinterability is examined and the synthesis route leading to dense, nanostructured Y-TZP is reported.

\section{Experimental Procedure}

\subsection{Powder synthesis}

Appropriate amounts of $\mathrm{ZrCl}_{4}(>98 \%$ pure) and $\mathrm{YCl}_{3}(99.9 \%$ pure) for the preparation of TZP with 5 at $\% \mathrm{Y}$ on the $\mathrm{Zr}$-site were dissolved in a $\mathbf{0 . 2}$ $\mathbf{M}$ aqueous $\mathrm{HCl}$ solution. The solution was filtered and added drop-wise to an excess of a $25 \mathrm{wt} \%$ ammonia solution, with the $\mathrm{pH}$ maintained at a value $>11$. A precipitated gel was obtained and allowed to settle overnight, after which the clear supernatant was removed. The gel obtained was washed with water/ammonia mixtures until the washing liquid no longer became turbid on addition of $0.1 \mathrm{M} \mathrm{AgNO}$. This indicated that the washing liquid was chloride-free. The gel was subsequently
Table 1. Explanation of codes used

\begin{tabular}{lc}
\hline Code & Explanation \\
\hline AC & Air-crystallized \\
HC & Hydrothermally crystallized \\
MC & Methanol-crystallized \\
W & Water-washed \\
E & Ethanol-washed \\
SD & Supercritical drying \\
400 & Finally heat-treated at $400^{\circ} \mathrm{C}$ \\
\hline
\end{tabular}

filtered, redispersed and washed twice in ethanol. After drying at $120^{\circ} \mathrm{C}$, the gel was divided into four parts as follows.

(1) The first part was dry milled, calcined in static air at $500^{\circ} \mathrm{C}$ for $2 \mathrm{~h}$ and dry milled again (AC500) (explanation of codes is given in Table 1).

(2) The second part was used for hydrothermal crystallization in a stainless steel autoclave equipped with poly(tetrafluoroethylene) liner. Crystallization of the gel took place at $200^{\circ} \mathrm{C}$ for $2 \mathrm{~h}$ in a basic medium (ammonia solution) al a pressure of 20-30 bar. After hydrothermal treatment, the $\mathrm{pH}$ of the slurry was 9-11. The slurry was divided into three parts:

(a) one part was filtered, dried at $120^{\circ} \mathrm{C}$ and dry milled (HC-W);

(b) the second part was treated as above $(\mathrm{HC}-\mathrm{W})$ and additionally heat-treated at $400^{\circ} \mathrm{C}$ for $1 \mathrm{~h}(\mathrm{HC}-\mathrm{W} 400)$;

(c) the third part was redispersed and washed three times in ethanol, filtered and dried at $120^{\circ} \mathrm{C}$. The dried powder was subsequently dry milled and heattreated at $400^{\circ} \mathrm{C}$ for $1 \mathrm{~h}$ to remove residual organics (HC-E400).

(3) The third part was used for crystallization in methanol. Crystallization took place at $250^{\circ} \mathrm{C}$ for $2 \mathrm{~h}$ at a pressure of $130 \mathrm{bar}$. The powder was supercritically dried at the same temperature and pressure, dry milled and heat-treated at $400^{\circ} \mathrm{C}$ for $1 \mathrm{~h}$ (MC-SD400).

(4) The fourth part was also used for crystallization in methanol. Crystallization also took place at $250^{\circ} \mathrm{C}$ for $2 \mathrm{~h}$ at a pressure of 130 bar. After crystallization, the powder was washed three times in ethanol, dry milled and heat treated for $1 \mathrm{~h}$ at $400^{\circ} \mathrm{C}$ (MC-E400).

In all cases, dry milling was performed with zirconia balls.

For the above-mentioned syntheses, the effects of crystallization medium and post-hydrothermal crystallization treatments (washing, drying and/or temperature treatment) on powder and sintering characteristics were researched. 


\subsection{Green compact formation and sintering}

Green compacts were prepared by cold-isostatic pressing in two steps: initially at $80 \mathrm{MPa}$ and finally at $400 \mathrm{MPa}$ with a $3 \mathrm{~min}$ holding time. Sintering was studied by means of dilatometry using a Netzsch 402 E dilatometer. The dilatometer's thermocouple was carefully calibrated by the melting method proposed by Henderson et al. ${ }^{18}$ Densities were calculated from the green density and the observed linear shrinkage of the specimens, and corrected for thermal expansion and weight loss (due to removal of absorbed water). Final densities calculated in this way were in good agreement with those measured by Archimedes' technique (in $\mathrm{Hg}$ ). All experiments were performed using cylindrical specimens with initial dimensions $7-15 \mathrm{~mm}$ (height) by 6-7 mm (diameter).

Non-isothermal sintering experiments were done at a heating rate of $120^{\circ} \mathrm{C} \mathrm{h}^{-1}$ to $1200^{\circ} \mathrm{C}$, immediately followed by cooling with a rate of $240^{\circ} \mathrm{C} \mathrm{h}^{-1}$. Isothermal experiments were done at $1050^{\circ} \mathrm{C}$ for 5 $\mathrm{h}$ and at 1070 and $1150^{\circ} \mathrm{C}$ for $10 \mathrm{~h}$ (heating rate $120^{\circ} \mathrm{h}^{-1}$, cooling rate $240^{\circ} \mathrm{C} \mathrm{h}^{-1}$ ).

\subsection{Characterization techniques}

A PL Thermal Sciences system (STA 625) was used for thermogravimetric and differential thermal analysis (TGA/DTA) (in air, heating rate $600^{\circ} \mathrm{C}$ $h^{-1}$ ). Nitrogen sorption isotherms were obtained at $77 \mathrm{~K}$ using a Micromeretics ASAP 2400 system. Specific surface areas were calculated by the BET method; no corrections for microporosity were necessary. Mesopore size distributions were calculated from the adsorption branch assuming cylindrical pore shape. The phase composition was analysed by X-ray diffraction (XRD) using a Philips PW 1370 diffractometer with $\mathrm{Cu} K_{\alpha}$ radiation. Peaks were corrected for the $K_{\alpha 1} / K_{\alpha 2}$ doublet and instrumental broadening. Crystallite sizes of the powders were determined by X-ray line broadening assuming Cauchy line profiles. Grain sizes in sintered specimens were determined by the lineal intercept technique from scanning electron micrographs (Hitachi S800) of polished, thermally etched cuts using $D=1.56 L$, where $L$ is the average lineal intercept. ${ }^{19}$ Corrections for residual porosity were made by the method proposed by Wurts and Nelson. ${ }^{20}$ The surfaces of specimens for examination by scanning electron microscopy (SEM) were coated with $\mathrm{Au} / \mathrm{Pd}$ to prevent charging.

\section{Results}

\subsection{Powder characteristics}

Phase analysis by XRD revealed that all powders are tetragonal with only traces of monoclinic zirconia. The primary crystallite size as calculated from X-ray line broadening data (XRLB) of the AC500, HC-W, HC-W400 and HC-E400 powders is $\sim 8 \mathrm{~nm}$, while that of the MC-SD400 and MCE400 powders is $\sim 5 \mathrm{~nm}$.

DTA/TGA analyses were performed in air up to $800^{\circ} \mathrm{C}$ for all powders before heat treatment or calcination. The DTA pattern of the AC powder showed three peaks at 300,430 and $475^{\circ} \mathrm{C}$. The first two peaks are related to the oxidative decomposition of ethoxy groups; the peak at $475^{\circ} \mathrm{C}$ coincides with the crystallization temperature of zirconia..$^{11,12,15}$ The total weight loss of this material upon heating is $25 \%$. The DTA pattern for HC-W material did not show any peaks. The weight loss of this material upon heating was only $4 \%$. The DTA pattern of the HC-E powder showed two peaks at 310 and $380^{\circ} \mathrm{C}$. The TGA pattern of the HC-E powder shows a distinct decrease in weight of $\sim 1.5 \%$ between 300 and $400^{\circ} \mathrm{C}$. Both peaks observed in the DTA pattern are therefore likely to be related to the oxidative decomposition of chemisorbed ethoxy groups. The total weight loss of the HC-E material upon heating is $5 \%$. The MC-SD material shows two peaks in the DTA pattern at 310 and $420^{\circ} \mathrm{C}$. These peaks correspond to a strong weight loss and are probably related to adsorbed methanol groups. The total weight loss of the material upon heating is $14 \%$. The DTA pattern of the MC-E powder showed only a single peak at $420^{\circ} \mathrm{C}$; weight loss upon heating for this material is $16 \%$.

As a consequence of the DTA results, the AC powder was calcined at $500^{\circ} \mathrm{C}$ (AC500) to make sure that all powder crystallized. The HC-E powder was treated at $400^{\circ} \mathrm{C}$ (HC-E400) in order to eliminate the chemisorbed ethoxy groups. The MC-SD and MC-E powders were both treated at $400^{\circ} \mathrm{C}$. DTA measurements performed after these heat treatments indicated that the powders were free of chemisorbed species and were fully crystalline.

The specific surface area of the powders is dependent on the crystallization medium. Crystallization in methanol (samples MC-E400 and MCSD400) results in the largest surface area and the smallest average crystallite size, as shown in Table 2. After heat treatment at $400^{\circ} \mathrm{C}$, the specific surface areas of both HC-E400 and HC-W400 are equal $\left(91 \mathrm{~m}^{2} \mathrm{~g}^{-1}\right)$.

Assuming that the volume $V_{\mathrm{p}}$ of the pores measured by $\mathrm{N}_{2}$ adsorption/desorption can be ascribed to (intra)-agglomerate porosity, the porosity $P$ was calculated using. ${ }^{\text {? }}$

$$
P=\frac{V_{\mathrm{p}} \rho_{\mathrm{th}}}{\left(V_{\mathrm{p}} \rho_{\mathrm{th}}+1\right)}
$$


Table 2. Powder and agglomerate properties of the powders investigated [ $S_{\mathrm{BET}}$ is specific surface area; $P$ is agglomerate porosity; $P_{\mathrm{y}}$ is yield point; $m$ is constant from eqn (2)]

\begin{tabular}{|c|c|c|c|c|c|c|}
\hline $\begin{array}{l}\text { Material } \\
\text { code }\end{array}$ & $\begin{array}{c}\text { Crystallite } \\
\text { size } \\
(\mathrm{nm})\end{array}$ & $\underset{\left(m^{2} g^{-1}\right)}{\mathbf{S}_{B E T}}$ & $\mathrm{P}(\%)$ & $\begin{array}{c}\mathbf{P}_{y} \\
(M P a)\end{array}$ & $\mathrm{m}$ & $\begin{array}{c}\text { Modus } \\
\text { pore } \\
\text { size } \\
(\mathrm{nm})\end{array}$ \\
\hline AC500 & 8 & 103 & 73 & 80 & 14 & $9 \cdot 5$ \\
\hline HC-W & 8 & 117 & 56 & 62 & 8 & 6.5 \\
\hline HC-W400 & 8 & 91 & 56 & 130 & 7 & $9 \cdot 5$ \\
\hline HC-E400 & 8 & 91 & 67 & 64 & 11 & 9.5 \\
\hline MC-SD400 & 5 & 144 & 77 & 41 & 11 & 6.5 \\
\hline MC-E400 & 5 & 144 & 77 & 55 & 12 & $6 \cdot 5$ \\
\hline
\end{tabular}

where $\rho_{\mathrm{th}}$ is the theoretical density $\left(6.06 \mathrm{~g} \mathrm{~cm}^{-3}\right)$. In Table 2, it can be seen that the agglomerate porosities are in the range 56 to $77 \%$ for all powders. These results indicate that the agglomerate porosity is dependent on both crystallization medium (air, water or methanol) and washing liquid used before final heat treatment. The largest porosities $(77 \%)$ are obtained for methanol crystallized materials (MC); the supercritical drying after treatment (MC-SD400) did not affect the final porosity.

\subsection{Compaction behaviour}

The relative density of the powders as a function of the logarithm of isostatic compaction pressure is given in Fig. 1. The curves show two linear parts (parts 1 and 2) with a point of intersection at pressure $P_{\mathrm{y}}$. Below $P_{\mathrm{y}}$, the increase in density is rather low.

According to Van de Graaf et al., ${ }^{21}$ the intersection $P_{y}$ is a measure of the strength of the agglomerates. After compaction at a pressure around $P_{\mathrm{y}}$, the agglomerates are gradually fragmented, while they are only rearranged at pressures below $P_{y}$. Above $P_{y}$, rearrangement of the internal agglom-

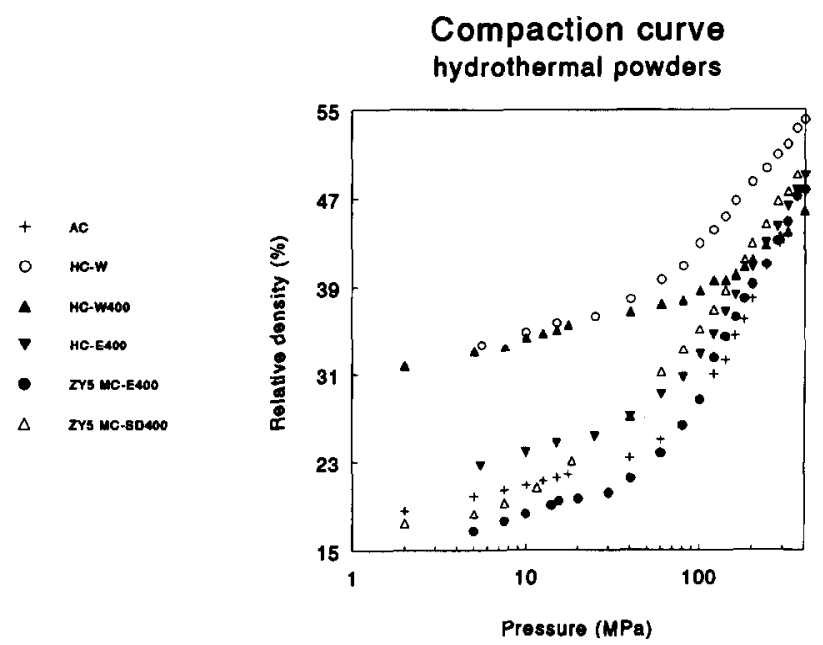

Fig. 1. Densification behaviour of the ZY5 powders during isostatic compaction. erate structure takes place. This part of the compaction curve (part 2) can be described by the empirical equation. ${ }^{7,12,22,23}$

$$
\rho-\rho_{\mathrm{y}}=m \times \ln \left[P / P_{\mathrm{y}}\right]
$$

where $m$ is a constant, $\rho$ the density and $P$ the pressure. The subscript $y$ stands for yield point. The values of $P_{\mathrm{y}}$ and $m$ are given in Table 2 . The $P_{y}$ values of the HC-W and the AC500 powder are 62 and $80 \mathrm{MPa}$, respectively. Because the HC-W powder shows a lower agglomerate porosity and the same crystallite size, the lower $P_{\mathrm{y}}$ value for the $\mathrm{HC}-\mathrm{W}$ powder can be related to weaker intercrystalline bonds in the $\mathrm{HC}-\mathrm{W}$ powder than in the AC500 powder. This is in accordance with results reported by Haberko and Pyda, ${ }^{13}$ who studied hydrothermal crystallization of $\mathrm{ZrO}_{2}-\mathrm{CaO}$.

If $\mathrm{HC}-\mathrm{W}$ and $\mathrm{HC}-\mathrm{W} 400$ are compared it is clear that the heat treatment at $400^{\circ} \mathrm{C}$ results in a strengthening of the intercrystalline bonds, because agglomerate porosity and crystallite size remain the same while $P_{y}$ increases. The influence of washing medium used after hydrothermal crystallization on agglomerate strength is demonstrated by the powders HC-W400 and HC-E400, which have an agglomerate strength of 130 and $64 \mathrm{MPa}$, respectively. The smaller agglomerate strength of HC-E400 is, in this case, probably related to the larger agglomerate porosity and/or a difference in strength of the intercrystalline bonds. The slightly higher agglomerate strength of the HC-E400 material compared with the MC-E400 material is probably related to the smaller agglomerate porosity of the former. The agglomerate strength of the MC-SD400 material $\left(P_{y}=41 \mathrm{MPa}\right)$ is smaller than of the MC-E400 material $\left(P_{\mathrm{y}}=55\right.$ $\mathrm{MPa})$. This shows the influence of supercritical drying in this case.

A large value of $m$ (the slope of the high pressure curve) corresponds to a relatively rapid increase in relative density with compaction pressure. A large value of $m$ might be an indication of a large 
density distribution in the green compact. Some sources of density variations are the friction between the powder and the die wall and between the powder particles. The specimen may fracture during unloading or ejecting of the pressed part, especially when large specimens are made. The $m$ values of the various powders range between 7 and 14 , as can be seen in Table 2. It is expected that the stresses created during compaction of the HC-W and HC-W400 material are small, therefore it should be easy to prepare large samples of this material.

\subsection{Green compact properties}

Figure 2 shows adsorption/desorption isotherms of green compacts (pressed at $400 \mathrm{MPa}$ ). The shape of the hysteresis loop is an indication of the pore morphology. The hysteresis of the HC-W and MC-SD400 materials is predominantly of type E, following the classification of De Boer. ${ }^{24}$ The AC500 material is of a mixed type $\mathrm{A} / \mathrm{E}$, while the MC-E400 and HC-E400 $(\approx \mathrm{HC}-\mathrm{W} 400)$ materials are in between (curves of the HC-W400 and MC-E400 materials are not shown here). Type E is indicative of tubular capillaries with strongly varying widths (as expected in powder compacts), while type A corresponds to a cylindrical pore shape. During sintering of a AC500 powder compact, the hysteresis shape becomes more and more similar to type A due to progressive neck formation. ${ }^{25}$ The differences in green porous texture between the powders are most probably caused by partial sintering already taking place during crystallization in air $\left(500^{\circ} \mathrm{C}\right)$ or heat treatment $\left(400^{\circ} \mathrm{C}\right)$ after crystallization in water or methanol of the normal dried powder, while partial sintering does not take place when the hydrothermally crystallized powder is only filtered and dried at $120^{\circ} \mathrm{C}$ (HC-W). Neck formation during heat treatment is reduced in the case of supercritical drying

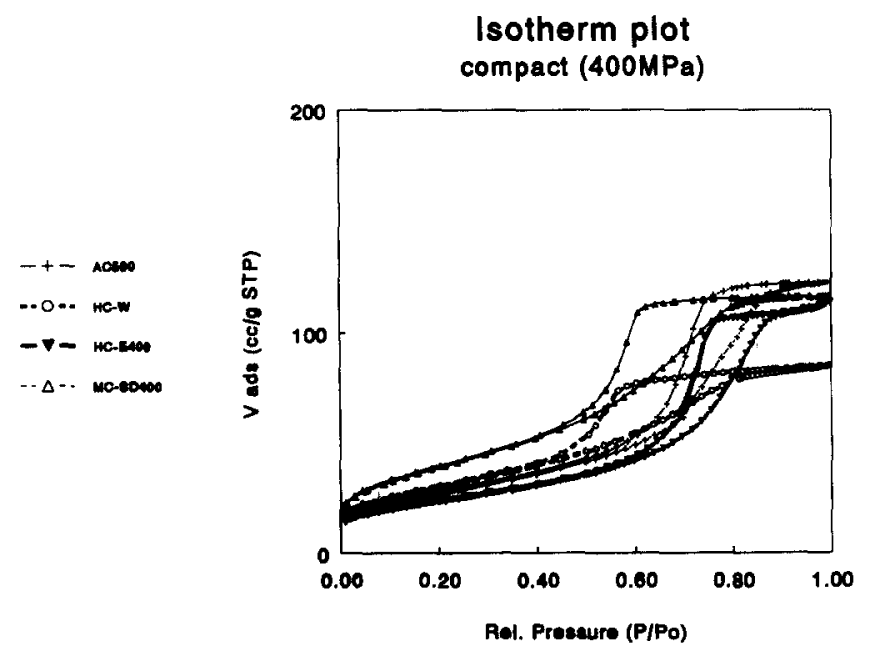

Fig. 2. $\mathrm{N}_{2}$ sorption isotherms of green compacts.

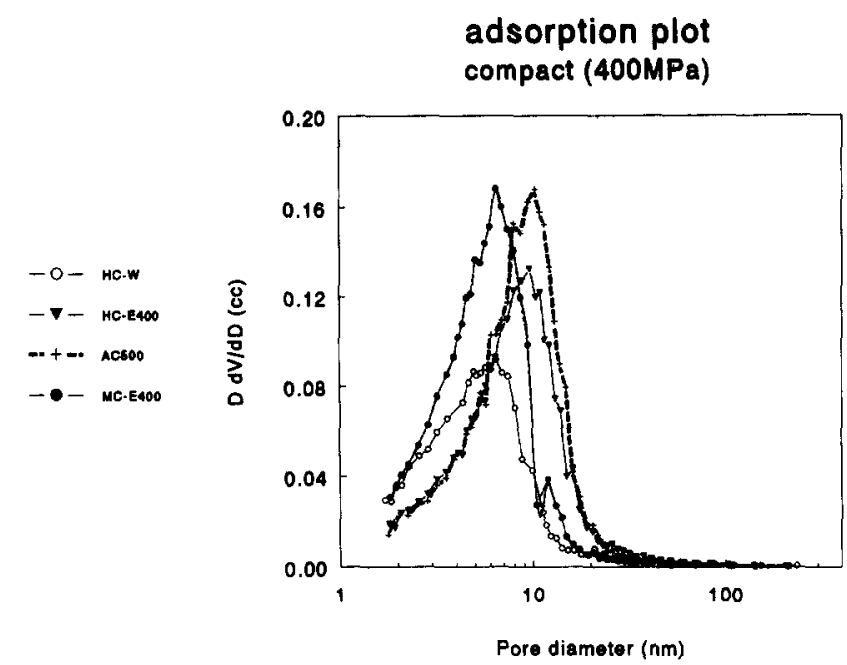

Fig. 3. Pore size distributions in the powder compacts after isostatic pressing at $400 \mathrm{MPa}$.

(MC-SD400), resulting in an E type hysteresis and low $P_{\mathrm{y}}$ values.

The pore size distributions of green compacts are given in Fig. 3. The width of the pore size distribution is similar for all powders, with the exception of the HC-W powder, which has a slightly broader distribution. The most frequently found pore diameter of the HC-E400, HC-W400 and AC500 compacts is the same and equals $9.5 \mathrm{~nm}$, whereas the HC-W, MC-SD400 and MC-E400 materials have a maximum at $6.5 \mathrm{~nm}$. Since the crystallite sizes of the AC500, HC-W, HC-W400 and HC-E400 materials are the same, the smaller average pore diameter of the HC-W green compact results from improved compactability resulting in a better particle stacking.

\subsection{Sinterability and microstructure}

The increase in relative density with temperature was measured using a heating rate of $120^{\circ} \mathrm{C} \mathrm{h}^{-1}$ to $1200^{\circ} \mathrm{C}$. The results for the AC500, HC-W, HC-W400 and MC-SD400 materials can be seen in Fig. 4.

\section{Densification curve}

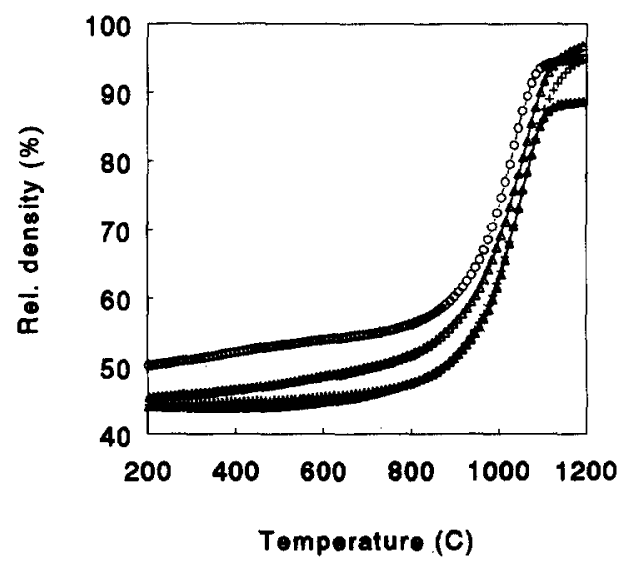

Fig. 4. Increase of relative density with temperature during heating at $120^{\circ} \mathrm{C} \mathrm{h}^{-1}$ 
The HC-E400 and MC-E400 materials show approximately the same densification behaviour as the AC500 material. The maximum in densification rate is found at a temperature of around $1040^{\circ} \mathrm{C}$ for all cases. The $\mathrm{HC}-\mathrm{W} 400$ material has the lowest final density $(90 \%)$, probably due to the harder agglomerates present in the powder. The other materials show only small differences in sinterability, these samples being $95 \%$ dense at $1150^{\circ} \mathrm{C}$. From the non-isothermal sintering behaviour, it is evident that it should be possible

Densification curve $1050 \mathrm{C}$

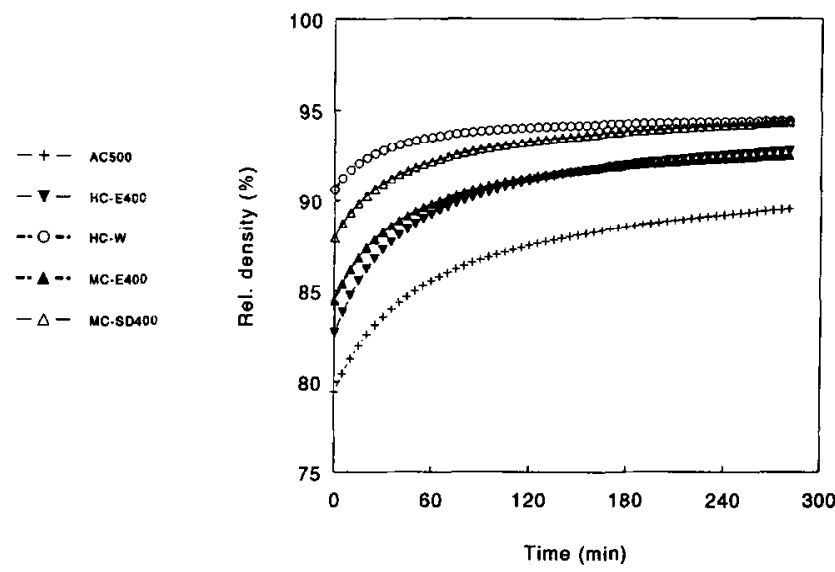

Fig. 5. Increase of relative density with time during sintering at $1050^{\circ} \mathrm{C}$.

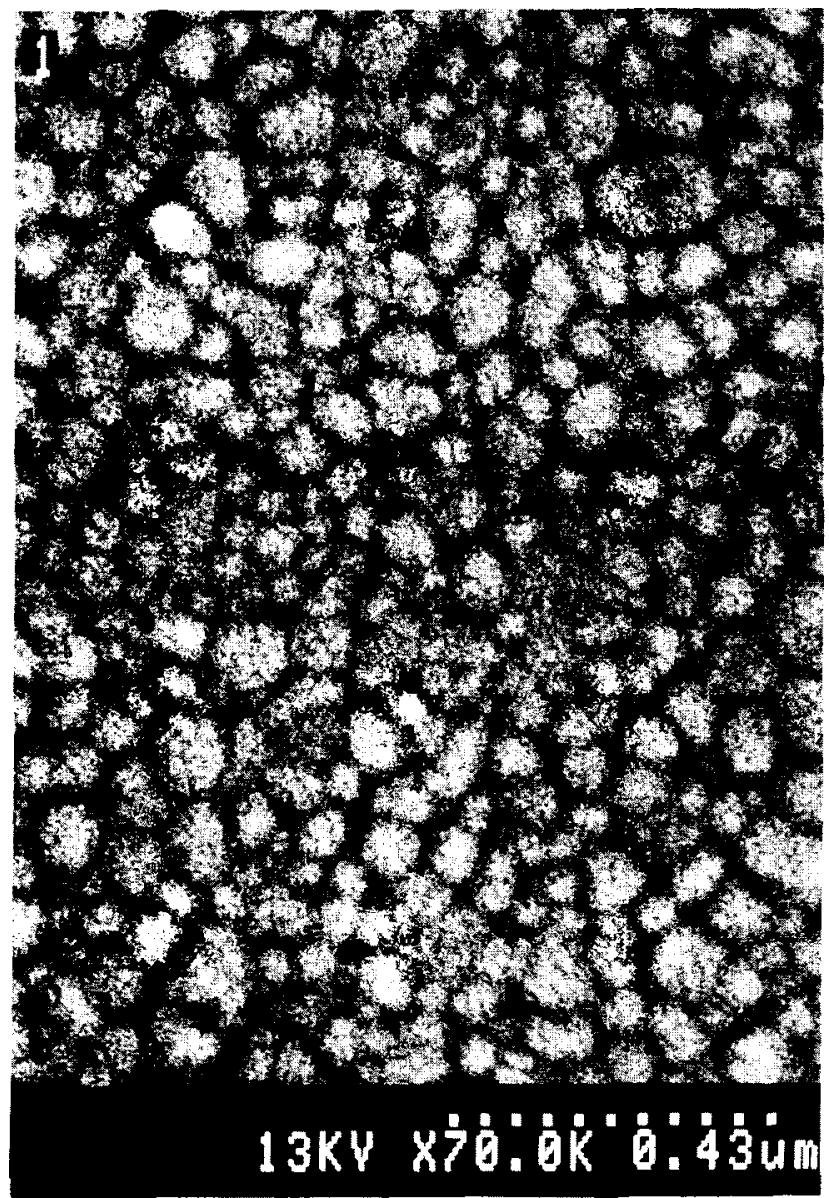

Fig. 6. Microstructure of the $\mathrm{HC}-\mathrm{E} 400$ material sintered for $5 \mathrm{~h}$ at $1050^{\circ} \mathrm{C}$. to sinter the five systems to full density at a temperature below $1100^{\circ} \mathrm{C}$. For the AC500, HC-W, HC-E400, MC-E400 and MC-SD400 materials, isothermal sintering experiments were performed at $1050^{\circ} \mathrm{C}$. The increase in relative density with time during sintering at $1050^{\circ} \mathrm{C}$ is illustrated in Fig. 5. The AC500 material is $90 \%$ dense and the HC-E400, MC-E400 and MCSD400 materials are 93,93 and $94 \%$ dense, respectively, after $5 \mathrm{~h}$ of sintering. The $\mathrm{HC}-\mathrm{W}$ material is $94 \%$ dense after $2 \mathrm{~h}$ of sintering at this low temperature. The average grain size of the materials after sintering at $1050^{\circ} \mathrm{C} / 5 \mathrm{~h}$ is between 95 and $100 \mathrm{~nm}$ in all cases. The microstructure is homogeneous, as is shown for the HC-E400 material in Fig. 6. HC-E400 and MC-SD400 were also sintered at $1150^{\circ} \mathrm{C}$ for $10 \mathrm{~h}$, resulting in a density of $98 \%$ and a grain size of $180 \mathrm{~nm}$. Sintering the AC500 and $\mathrm{HC}-\mathrm{E} 400$ materials at $1070^{\circ} \mathrm{C}$ for $10 \mathrm{~h}$ resulted in a grain size between 120 and $130 \mathrm{~nm}$ and a relative density of 93 and $96 \%$ for AC500 and HC-E400, respectively. In the HC-W material, small cracks were observed by SEM, as is shown in Fig. 7. No cracking was observed for the other materials. A drawback of the AC500 material is that it results in irreproducible final densities. After sintering for $10 \mathrm{~h}$ at $1150^{\circ} \mathrm{C}$, densities varied between 92 and $97 \%$. The densification

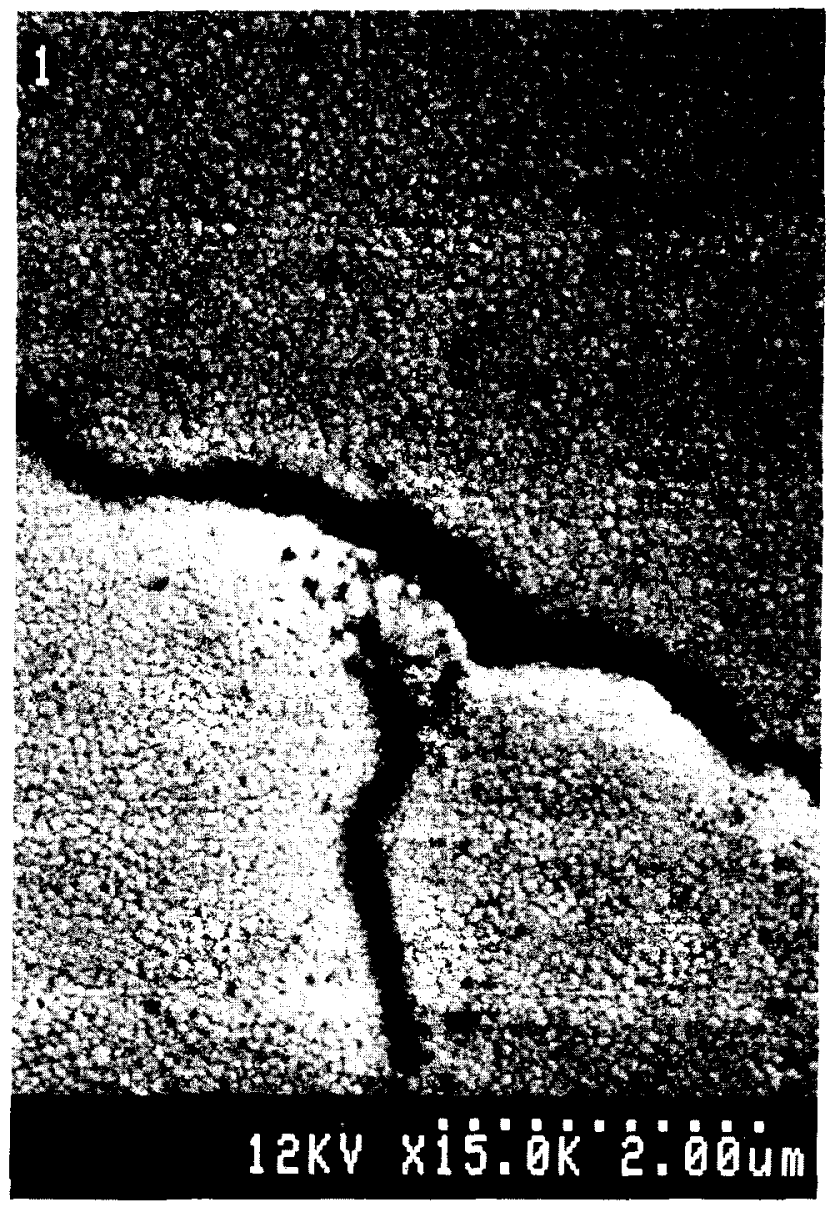

Fig. 7. Microstructure of the $\mathrm{HC}-\mathrm{W}$ material sintered at $1050^{\circ} \mathrm{C}$ for $5 \mathrm{~h}$ showing a crack. 
characteristics of the hydrothermal powders are very reproducible.

\section{Discussion}

\subsection{The effect of liquid medium before final heat treatment on powder properties}

Final heat treatment of hydrothermal powder results in a larger pore size and smaller pore size distribution. The neck area is also increased by this heat treatment. Boutz et al. ${ }^{25}$ observed that an increase in heat treatment temperature of an aircrystallized powder compact (starting at $500^{\circ} \mathrm{C}$ ) leads to an increase in pore size, narrowing of the pore size distribution and increase in neck area. The results observed for the HC-W and HC-W400 materials indicate that the same holds for hydrothermally crystallized powders for temperatures down to $200^{\circ} \mathrm{C}$ (hydrothermal crystallization temperature). After hydrothermal crystallization, the liquid medium does not influence the pore size, pore size distribution or the pore shape. Materials HC-W400 and HC-E400 show identical results

The agglomerate strength of air-crystallized powder can be reduced if water is replaced by ethanol before crystallization. This reduction is extremely large. It was found that the agglomerate strength of a water-washed air-crystallized powder is $>400 \mathrm{MPa}$, whereas the agglomerate strength of ethanol-washed air-crystallized powder varies between 60 and $90 \mathrm{MPa}$. This reduction in strength has been ascribed to the formation of ethoxide groups on the surface ${ }^{8}$ and to the lower compaction pressure during drying due to the lower surface tension of ethanol compared with water. ${ }^{9,10}$ In the case of hydrothermally crystallized powder, the agglomerate strength is reduced to a lesser extent if water is replaced by ethanol after crystallization: $130 \mathrm{MPa}$ for HC-W400 compared with $64 \mathrm{MPa}$ for HC-E400 powder. This means that the effect of the washing medium can be reduced by crystallization before final heat treatment. However, this influence cannot be neglected yet. The reduction in agglomerate strength is likely to result from the increase in agglomerate porosity. The increase of agglomerate strength with heat treatment temperature (HC-W and $\mathrm{HC}-\mathrm{W} 400)$ is caused by an increase in neck area.

The hydrothermally crystallized powders show good sintering characteristics. The observed cracking of the HC-W material might be related to stresses forming in the temperature range 200 $700^{\circ} \mathrm{C}$ during densification of agglomerates containing a large number of pores with a diameter $<6 \mathrm{~nm}$. Cracking of the $\mathrm{HC}-\mathrm{W}$ material can be avoided if a lower heating rate is used until $700^{\circ} \mathrm{C}$.

\subsection{The effect of crystallization medium on powder properties}

A comparison will be made between crystallization in air, water and methanol. Crystallization in methanol results in a smaller crystallite size than is obtained by hydrothermal crystallization or crystallization in air. The difference in pore size between AC500 and HC-E400 on one hand, and MC-E400 on the other hand might be caused by this difference in crystallite size.

More neck area is obtained by crystallization in air than by crystallization in liquid media. This might be caused by the higher crystallization temperature. To a large extent, the strength of the intercrystalline bonds and agglomerate porosity determine the agglomerate strength of the material. ${ }^{5}$ It is reasonable to assume that the strength of the intercrystalline bonds is increased if the neck area is increased. Therefore, the agglomerate strength of the methanol-crystallized material is expected to be the smallest; this is in agreement with experimental results (as indicated by $P_{\mathrm{y}}$ values).

The sinterability of the material is not influenced by the crystallization medium. The low reproducibility of achieving high final densities of the aircalcined material can have several causes. Some of these are: a large agglomerate-strength distribution; the irregular agglomerate shape; and the large differences in agglomerate sizes in the powder. The synthesis of Y-TZP with reproducible high final densities from air-crystallized material is still under investigation.

\subsection{The effect of supercritical drying of methanol- crystallized material on powder properties}

The effect of supercritical drying on powder properties has been analysed for methanol-crystallized material. The results obtained for the methanolcrystallized materials show that supercritical drying has no influence on pore size, pore size distribution, agglomerate porosity or sinterability of the material. Supercritical drying does, however, result in less neck area compared with normal drying which, with the same agglomerate porosity, leads to a smaller agglomerate strength. This will lead to a more homogeneous microstructure in the green and sintered compact.

\section{Conclusions}

(1) Pressureless sintering of the hydrothermally or methanol-crystallized material that was ethanol-washed and subsequently heat-treated, results in relatively dense (93-94\%), nanostructured $(<100 \mathrm{~nm}) \mathrm{Y}$-TZP at a sintering temperature as low as $1050^{\circ} \mathrm{C}$. 
(2) Densities can be increased to $96 \%$ at $1070^{\circ} \mathrm{C}$ and $98 \%$ at $1150^{\circ} \mathrm{C}$, with resulting grain sizes of 130 and $180 \mathrm{~nm}$, respectively.

(3) The as-dried hydrothermally crystallized material (HC-W) exhibited small cracks after sintering, probably caused by stresses associated with the densification of agglomerates. Cracking can be avoided by low heating rates up to $700^{\circ} \mathrm{C}$.

(4) The effects of supercritical drying after crystallization in methanol are minor.

(5) The powder characteristics, compactability, green compact properties and sinterability of the air-calcined and hydrothermally crystallized materials that were ethanol-washed and heat-treated, are almost the same.

(6) Crystallization in methanol instead of water or air results in smaller crystallites and softer agglomerates.

(7) Replacing water by ethanol directly after hydrothermal crystallization results in an increase in agglomerate porosity.

\section{Acknowledgements}

These investigations were partly supported by the Innovative Research Program on Technical Ceramics (IOP-TK) with financial aid from the Dutch Ministry of Economic Affairs.

\section{References}

1. Burggraaf, A. J., Stuijts Memorial Lecture 1991: Some new developments in ceramic science and technology. J. Eur. Ceram. Soc., 9 (1992) 245-50.

2. Burggraaf, A. J., Winnubst, A. J. A. \& Verweij, H., Dense and porous nanostructured ceramics and composites. In Proceedings of the Third Meeting of the European Ceramic Society, ed. P. Duran \& J. F. Fernandez. Faenza Editrice Iberica, 12-17 1993, pp. 561-76.

3. He, Y. J., Winnubst, A. J. A., Burggraaf, A. J., Verweij, H., van der Varst, P. G. Th. \& De With, B. G., Grain size dependence of sliding wear in tetragonal zirconia polycrystallines. Submitted to J. Am. Ceram. Soc.

4. Theunissen, G. S. A. M., Microstructure, fracture toughness and strength of (ultra)fine-grained tetragonal zirconia ceramics. PhD thesis, University of Twente, Enschede, The Netherlands, 1991, Ch. 7.

5. Rumf, H., Grundlagen und Methoden des Granulierens. Chemie Ing. Techn., 30 (1958) 144-58.

6. Haberko, K., Characteristics and sintering behavior of zirconia ultrafine powders. Ceramurgia Int., 5 (1979) $145-58$.

7. Groot Zevert, W. F. M., Winnubst, A. J. A., Theunissen, G. S. A. M., \& Burggraaf, A. J., Powder preparation and compaction behaviour of fine-grained Y-TZP. J. Mater. Sci., 25 (1990) 3449-55.
8. Kaliszewski, M. S. \& Heuer, A. H., Alcohol interaction with zirconia powder. J. Am. Ceram. Soc., 73 (1990) 1504-9.

9. Roosen, A. \& Hausner, H., The influence of processing conditions on the sintering behaviour of coprecipitated calcia-stabilized zirconia powders. In Ceramic Powders (Materials Science Monographs 16), ed. P. Vincenzini. Elsevier, Amsterdam, 1983, pp. 773-82.

10. Dogan, F. \& Hausner, H., The role of freeze-drying in ceramic powder processing. In Ceramic Trans., Ceramic Powder Science (II), Vol. 1, ed. G. L. Messing, E. R. Fuller Jr \& H. Hausner. American Ceramics Society, Westerville, $\mathrm{OH}, 1988$, pp. 127-34.

11. Mercera, P. D. L., Van Ommen, J. G., Doesburg, E. B. M., Burggraaf, A. J. \& Ross, J. R. H., J. Mater. Sci., 27 (1992) 4890.

12. Theunissen, G. S. A. M., Microstructure, fracture toughness and strength of (ultra)fine-grained tetragonal zirconia ceramics. PhD thesis, University of Twente, Enschede, The Netherlands, 1991, Ch. 2.

13. Haberko, K. \& Pyda, W., Preparation of Ca-stabilized $\mathrm{ZrO}_{2}$ micropowders by a hydrothermal method. In Advances in Ceramics, vol. 12, American Ceramics Society, Westerville, $\mathrm{OH}, 1984$, p. 774-83.

14. Pyda, W., Haberko, K. \& Bucko, M. M., Hydrothermal crystallization of zirconia and zirconia solid solutions. $J$ Am. Ceram. Soc., 74 (1991) 2622-9.

15. Boutz, M. M. R., Olde Scholtenhuis, R. J. M., Winnubst, A. J. A. \& Burggraaf, A. J., A hydrothermal route for production of dense, nanostructured Y-TZP. Mater. Res. Bull., 29 (1994) 31-40.

16. Rossi, G. A. \& Pelletier, P. J., $\mathrm{Y}_{2} \mathrm{O}_{3}$ doped $\mathrm{ZRO}_{2}$ powder prepared in nonaqueous medium. Influence of the crystallization method on powder sinterability and properties of Y-TZP ceramics. In Advances in Ceramics, Vol. 24: Science and Technology of Zirconia III, ed. S. Somiya, N. Yamamoto \& H. Yanagida. American Ceramics Society, Westerville, OH, 1988, pp. 173-81

17. Sato, T., Dosaka, K., Yoshioka, T., Okuwaki, A., Torii, K. \& Onodera, Y., Sintering of ceria doped tetragonal zirconia crystallized in organic solvents, water, and air. $J$. Am. Ceram. Soc., 75 (1992) 552-6.

18. Henderson, J. B., Emmerich, W.-D. \& Wassmer, E., A method for the temperature calibration of pushrod dilatometers. J. Thermal Anal., 32 (1987) 1905-13.

19. Mendelson, M. I., Average grain size in polycrystalline ceramics. J. Am. Ceram. Soc., 52 (1969) 443-6.

20. Wurts, J. C. \& Nelson, J. A., Lineal intercept technique for measuring grain size in two-phase polycrystalline ceramics. J. Am. Ceram. Soc., 55 (1972) 109.

21. Van de Graaf, M. A. C. G., Ter Maat, J. H. H. \& Burggraaf, A. J., Microstructure and sintering kinetics of highly reactive $\mathrm{ZrO}_{2}-\mathrm{Y}_{2} \mathrm{O}_{3}$ ceramics. J. Mater. Sci, 20 (1985) 1407-18

22. Halloran, J. W., Role of powder agglomerates in ceramic processing. In Advances in Ceramics, Vol. 9, ed. J. A. Mangels \& G. L. Messing. American Ceramics Society, Inc., Columbus, $\mathrm{OH}, 1984$, pp. 67-75.

23. Halloran, J. W., Agglomerates and agglomeration in ceramic processing. In Ultrastructure Processing of Ceramics, Glasses and Composites, ed. L. L. Hench \& D. R. Ulrich. John Wiley and Sons, New York, 1984, pp. 404-17.

24. De Boer, J. H., The Structure and Properties of Porous Materials. Butterworth Scientific Publications, 1958, pp. 68-93.

25. Boutz, M. M. R., Winnubst, A. J. A. \& Burggraaf, A. J., Yttria-ceria stabilized tetragonal zirconia polycrystals sintering, grain growth and grain boundary segregation. J. Eur. Ceram. Soc., 13 (1994) 89-102. 